\title{
In vitro fertilization in thrombophilic patients
}

\author{
Cristina Terumy Okamoto', Fernando Sakata Belizário², Mauren Beatriz Frazon Carbonar², \\ Ricardo Teodoro Beck², Theodoro Busso Beck Neto², Vanessa Caroline Portugal ${ }^{2 \star}$ \\ ${ }^{1}$ Universidade Positivo (UP), Department of Medicine, Curitiba, PR, Brazil \\ ¿Universidade Positivo (UP), Curitiba, PR, Brazil \\ ${ }^{3}$ Hospital Maternidade Curitiba, Centro de Reprodução Dr. Ricardo Beck, Curitiba, PR, Brazil
}

\begin{abstract}
Objectives: To verify the in vitro fertilization success rates in patients with thrombophilia and compare it to a control group. Material and methods: Analysis of the records of patients submitted to in vitro fertilization between January 2011 and December 2014. The study group was comprised of 47 patients with thrombophilia and the control group was comprised of 223 patients without thrombophilia. Results: The thrombophilic patients age varied from 28 to 48 years, with average age of 35 years. The number of fertilization attempts varied from 1 to 6 , with average of 2.11. The control group age varied from 22 to 63 years, with average of 36 years. The number of attempts varied from 1 to 4 , with average of 1.28 . Only $6.3 \%$ of the positive beta hCG results belonged to thrombophilic patients, while $32.7 \%$ of the negative results belonged to the study group. A high incidence of MTHFR mutations was found (61.7\%), but the frequency of the factor V Leiden was not significant (2.1\%). Conclusions: The patients with thrombophilia have lower success rates on in vitro fertilization procedures. The most frequent mutation was MTHFR C677T. There was no prejudice on the quality or quantity of oocytes.
\end{abstract}

Keywords: in vitro fertilization; IVF; thrombophilia.

\section{Introduction}

The thrombophilia has been identified with higher frequency in women with implantation failure submitted to repeated IVF cycles, when compared with fertile women. ${ }^{1}$

Pregnancy is a hypercoagulability state, and thrombophilias are a group of coagulation disorders, which predispose the thrombotic events. Although the mechanism is not well known, mutations in the genes related with coagulation may cause damage to chorionic vascularization, reduce the trophoblastic invasion, lead to apoptosis and poor placental circulation, due to placental thrombosis. ${ }^{1,2}$

In repeated abortion as in repeated failure IVF cycles, the patients should be blood tested for thrombophilia and antiphospholipid antibodies. ${ }^{3}$ However it is important to consider the limitations of these tests. A negative result does not exclude the possibility of a hereditary predisposition to thrombosis, unless there has been tested a specific hereditary defect for thrombophilia in a family with an already known condition. The personal and family backgrounds of thrombosis are commonly more important than the result of the thrombophilia test, since a negative result cannot exclude the disease. Moreover patients without personal or family background of thrombosis don't have recommendation of thrombophilia investigation. ${ }^{4,5}$

The investigation includes hereditary and acquired factors. The hereditary factors are: Leiden factor $\mathrm{V}$, factor II of prothrombin gene G20210A, MTHFR C677T and A1298C mutation, functional protein C, free protein S and antithrombin III.

\section{Financial support: None.}

Submitted: February 08, 2017.

Accepted: October 18, 2017

The study was carried out at Universidade Positivo (UP), Curitiba, PR, Brazil.

Copyright Okamoto et al. This is an Open Access article distributed under the terms of the Creative Commons Attribution License, which permits unrestricted use, distribution, and reproduction in any medium, provided the original work is properly cited. 
The acquired factors are: homocysteine, antibodies to antiphospholipid antibodies syndrome - lupus anticoagulant; anticardiolipin IgG and IgM, and Beta-2 glycoprotein 1 antibodies IgM and IgG. ${ }^{6}$

Several studies points to an increased prevalence of coagulation mutations in patients with repeated negative results in IVF cycles. In a study of Karatas et al., ${ }^{2}$ a retrospective cohort study based on data collected from 142 couples with recurrent pregnancy loss, analyzing the frequency of the Leiden factor V, MTHFR and the factor II of prothrombin gene G20210A. Most women of the study (64.1\%) had at least one of the three mutations related with thrombophilia. All cases with mutation of the factor II gene had more than three miscarriages, occurred between the $6^{\text {th }}$ and $8^{\text {th }}$ weeks of pregnancy.

\section{Objectives}

To analyse the success rate of in vitro fertilization (IVF) in women with thrombophilia that undergone to one or more unsuccessful IVF cycles, comparing with the success rate of non-thrombophilic IVF patients and with literature data.

\section{Material and methods}

This was an observational cross-sectional study, with retrospective data collection from patients submitted to in vitro procedures at Dr. Ricardo Beck Reproduction Center, in the Maternity Hospital Curitiba - Curitiba/PR. The clinical history were collected between January 2011 and December 2014.

The positive result of the $\beta$-hCG was compared between the study group ( $n=47$ patients with thrombophilia) versus the control group ( $n=223$ patients without thrombophilia).

The criteria to confirm the thrombophilia diagnosis consist in a clinical (previous miscarriage, DVT, premature birth in a previous pregnancy, and family history of the quoted data) and a laboratory factor. The laboratorial factors of the familial cases differ from those acquired. Familial factors: Leiden factor V; factor II of prothrombin gene G20210A; MTHFR C677T and A1298C; functional C protein, free protein S and antithrombin III. Acquired factors: homocysteine, antibodies to antiphospholipid antibodies syndrome - lupus anticoagulant; anticardiolipin IgG and IgM, and Beta-2 glycoprotein 1 antibodies IgM and IgG.

The inclusion criteria were: IVF clinical history of patients above 20 years old, with at least one previous IVF procedure.

The exclusion criteria were: clinical history of patients below 20 years old, smokers, incomplete clinical history, cycles without semen suitable for a successful fertilization.

\section{Results}

In the study group, the age ranged between 28 and 48 years old, with mean of 35 years old. The number of attempts ranged from 1 to 6 , and the mean, median, mode and standard deviation were respectively: $2.11 ; 2 ; 2$ and 1.09 . In the control group, the age ranged between 22 and 63 years old, with mean of 36 years old. The number of attempts ranged from 1 to 4, with a respectively mean, median, mode and standard deviation of $1.28 ; 1 ; 1$ and 0.55 .

The analysis of the number of oocytes in thrombophilic patients revealed a mean, median, mode, range and standard deviation respectively of 9, 8, 7, 10 (ranging from 3 to 13) and 3.7. In the control group the corresponding values were: $9,8,4,28$ (ranging from 2 to 30) and 4.7.

The general fecundity rate ranged from 0 to $100 \%$ per patient, with a mean of $90.3 \%$. The median and the mode had the same value (100\%); meanwhile the range was 100\%; and the standard deviation, 17.1. The group of thrombophilic patients showed a mean, median, mode respectively of $94.4 \%, 100 \%, 100 \%$, a range of $50 \%$ and 12.8 of standard deviation. The control group had mean, median, mode, range and standard deviation respectively of $89.5 \%, 100 \%$, $100 \%, 100 \%$ and 17.

The success rate was lower when compared with control group: among all the positives $\beta$-hCG exams, only $6.3 \%$ belong to thrombophilic patients, meanwhile in the negative exams, $32.7 \%$ belong to thrombophilic patients.

It has been found an increase frequency of alterations of the MTHFR among the thrombophilic patients (61.7\%), however the Leiden factor $V$ frequency was not relevant (2.1\%).

\section{Discussion}

Safdarian et al. ${ }^{1}$ in a cross-sectional study, compared 96 women with history of pregnancy loss and 95 control women. The study showed that there was at least one known risk factor for thrombophilia, being the Leiden factor $\mathrm{V}$ and the homozygous mutation of MTHFR commonly related with IVF failure.

Qublan et al. ${ }^{7}$ divided in group A ( $n=90$, women with 3 or more IVF failure), group $B(n=90$, women with a successful first IVF treatment) and group $C(n=100$, women who had at least one spontaneous pregnancy without complications 
and without miscarriage history) and tested them for the presence of hereditary (Leiden factor $\mathrm{V}$, prothrombin mutation, MTHFR and deficiency of protein S, C and antithrombin III) and acquired thrombophilic factor (lupus anticoagulant and anticardiolipin). The result revealed an increased incidence of Leiden factor $\mathrm{V}$, MTHFR and antiphospholipid antibodies in group A, when compared with the control groups. At least one thrombophilic factor, hereditary or acquired, was detected in $68.9 \%$ of women with previous IVF failures, meanwhile in the groups B and C this number was about $25 \%$. When assessed cases with 2 or more thrombophilic factors, the group A holds $35.6 \%$ against $4 \%$ of groups B and C.

In this study we have found a higher frequency of alterations in MTHFR among thrombophilic patients (61.7\%), but not of the Leiden factor V (2.1\%). Nevertheless, the data obtained meets the currently literature.

Based on the fecundity rate seen in thrombophilic patients, we may infer that the disease does not interfere in the oocyte quality of these patients. Ricci et al. ${ }^{4}$ achieved similar results comparing the oocytes of patients carrying the thrombophilic mutations with patients without mutations, with regards to number and quality of the cells.

The age of the patients does not seem to be a determinant factor between the groups, considering it was similar between the groups.

The higher number of IVF attempts in thrombophilic patients, shows that it is a characteristic interfering in the fertilization success. Probably, as supposed, the thrombophilia leads to a reduction of the trophoblastic invasion, apoptosis, damage to chorionic vascularization and poor placental circulation, through the placental thrombosis.

Therefore, the patients who present thrombophilia possess lower success rates in IVF procedures, with no alterations in the oocyte quality or quantity. The most common mutation for thrombophilia in these cases was the MTHFR C677T.

\section{References}

1. Safdarian L, Najmi Z, Aleyasin A, Aghahosseini M, Rashidi M, Asadollah S. Recurrent IVF failure and hereditary thrombophilia. Iran J Reprod Med. 2014;12(7):467-70. PMid:25114668.

2. Karatas A, Eroz R, Albayrak M, Ozlu T, Cakmak B, Keskin F. Evaluation of chromosomal abnormalities and common trombophilic mutations in cases with recurrent miscarriage. Afr Health Sci. 2014;14(1):216-22. PMid:26060483. http://dx.doi.org/10.4314/ ahs.v14i1.34.

3. Simon A, Laufer N. Repeated implantation failure: clinical approach. Fertil Steril. 2012;97(5):1039-43. PMid:22464086. http:// dx.doi.org/10.1016/j.fertnstert.2012.03.010.

4. Ricci G, Bogatti P, Fischer-Tamaro L, Giolo E, Luppi S, Montico M, et al. Factor V Leiden and prothrombin gene G20210A mutation and in vitro fertilization: prospective cohort study. Hum Reprod. 2011;26(11):3068-77. PMid:21868400. http://dx.doi.org/10.1093/ humrep/der261.

5. Rudick B, Su HI, Sammel MD, Kovalevsky G, Shaunik A, Barnhart K. Is factor V Leiden mutation a cause of in vitro fertilization failure? Fertil Steril. 2009;92(4):1256-9. PMid:19464002. http://dx.doi.org/10.1016/j.fertnstert.2009.03.089.

6. Azem F, Many A, Ben Ami I, Yovel I, Amit A, Lessing JB, et al. Increased rates of thrombophilia in women with repeated IVF failures. Hum Reprod. 2004;19(2):368-70. PMid:14747183. http://dx.doi.org/10.1093/humrep/deh069.

7. Qublan HS, Eid SS, Ababneh HA, Amarin ZO, Smadi AZ, Al-Khafaji FF, et al. Acquired and inherited thrombophilia: implication in recurrent IVF and embryo transfer failure. Hum Reprod. 2006;21(10):2694-8. PMid:16835215. http://dx.doi.org/10.1093/humrep/ del203.

\section{*Correspondence \\ Vanessa Caroline Portugal \\ Rua Retiro São José, 253, Vila Bancária, \\ CEP 83601-640, Campo Largo, PR, Brazil \\ Tel.: +55 (41) 98888-1885 \\ E-mail: vane.c.portugal@hotmail.com}

\section{Authors information}

CTO - Neonatology preceptor, Universidade Positivo (UP).

FSB, MBFC, TBBN and VCP - Physicians, Universidade Positivo (UP).

RTB - Physician, Hospital Maternidade Curitiba (HMC), Curitiba, PR, Brazil.

\section{Authors contribution}

CTO was responsible for general supervision of the research group. FSB, MBFC, RTB, TBBN and VCP provided and cared for study patients. 